\title{
Palliative Medicine: Politics and Policy
}

\author{
Diane E. Meier, M.D., ${ }^{1}$ David J. Casarett, M.D., ${ }^{2}$ Charles F. von Gunten, M.D., Ph.D., ${ }^{3}$ \\ Walter J. Smith, S.J., Ph.D., ${ }^{4}$ and C. Porter Storey Jr., M.D. ${ }^{5}$
}

Diane E. Meier, M.D. (Moderator): I have been in Washington, D.C. since October 2009, to begin a health policy fellowship. I will be actually living in D.C. for a year. Right now, I am interviewing for placements, either in a member's office or on one of the committees of jurisdiction for health care, like the House Committee on Ways and Means or the Senate HELP or Finance Committees. I am also interviewing with individual member's offices, including Senators Wyden, Rockefeller, Warner, and others.

It has been interesting to observe the reaction that people have when they read my resume and my cover letter-their reaction to the fact that I am a palliative care physician. Some are very positively engaged and ask a lot of questions about what palliative care is and how it is the same and different from hospice. Others make it perfectly clear that the issue isand this is my language-radioactive. This second group sees a risk of becoming a target for certain elements in our society whose goal is to defeat health care reform, and influence the 2010 midterm elections. Some may feel that just having the term palliative care attached to my name and then being attached to a Hill office is a risk too great to take.

That has been an interesting experience: to feel as if my welcome into some of these offices is influenced by the fact that I work in palliative care.

I would say the majority of the responses though are not constrained by worries about the term palliative care but rather are anxious to correct the record after what happened in August 2009. That has been heartening. I am looking forward to learning as much as I can over the next year about how process and politics influence health policy. I hope to develop a more nuanced and sophisticated understanding of the process and the politics, so that when the year is over our influence on important policy priorities for palliative care will be more effective.

Walter J. Smith, S.J., Ph.D.: The health care debate, however it ultimately plays out, has disposed an unparalleled opportunity for palliative care. Popular attention is now focused on the need to achieve a high-performance health care system. A large number of opinion leaders tend to favor some of the key issues to which palliative care is committed.

The Commonwealth Fund recently published a report citing that $76 \%$ of opinion leaders actually favor a health insurance plan that has a public option component to it. Because public awareness has been focused on these issues, palliative care has an opportunity to define itself as it has not been able to do as effectively before. All of the issues pertaining to quality of care in the public debate are precisely issues for which palliative care both advocates and is pledged.

Quality definitely is a very big concern for health care reform; cost effectiveness is also a key issue. Palliative care offers both.

C. Porter Storey Jr., M.D.: I am really interested in this "radioactivity" of palliative care. My first emotion when this death panel stuff came up was disgust. Nevertheless, it has caught so much national attention and it has come up over and over again. There was even Web chatter after the 60 Minutes program in November about "death panels" again, so I think that many people are concerned about the tension between a high-performing health care system and a very individual one.

I think what is coming to the surface is fear that there really is not enough money to do everything for everybody and that some mechanical, governmental method will be used to determine how much of our scarce health care resources will be applied to their situation.

I know the patients whom I see on an individual basis are quite concerned about this tension between doing the things that make sense to them and that are likely to help versus just trying to save money at their expense. A lot of our work clinically is helping people navigate through this difficult tension.

David J. Casarett, M.D.: I need to be clear that I cannot speak on the record for the Veterans Administration (VA), although because I work in a closed health care system, this is, I think, a chronic concern for all of us.

\footnotetext{
${ }^{1}$ Center to Advance Palliative Care; Hertzberg Palliative Care Institute, Departments of Geriatrics and Internal Medicine, Mount Sinai School of Medicine, New York, New York.

${ }^{2}$ Philadelphia VAMC, University of Pennsylvania, Division of Geriatric Medicine, Philadelphia, Pennsylvania.

${ }^{3}$ Institute for Palliative Medicine, San Diego Hospice, San Diego, California.

${ }^{4}$ HealthCare Chaplaincy, New York, New York.

${ }^{5}$ American Academy of Hospice and Palliative Medicine, Glenview, Illinois; Colorado Permanente Medical Group, Denver, Colorado.
} 
Diane E. Meier, M.D.: Could you just comment on the differences in the incentives and the oversight of what I would argue is a more rational approach to developing and administering a health care system, as opposed to the fee-for-service model in the rest of the country?

David J. Casarett, M.D.: I can comment on the VA's approach to end-of-life care, which I think really has been or should be a model to the rest of the country, if not the rest of the world. For instance, all veterans in any VA facility have access to a palliative care team if they want one. Would it not be great if all hospitals in the country had a palliative care team in place?

Also the approach the VA has taken to quality measurement, making sure that we have mechanisms in place to measure the quality of end-of-life care, not just measuring mortality rates but also measuring the quality of care that veterans get near the end of life. This is something that I think we would love to see outside of the VA health care system. I think what is happening now in the VA is at least 5 , if not 10 years or more away in the rest of the health care system.

In all the discussions that I have been involved with in the VA about end-of-life care, cost really is not an issue. The focus really has been on delivering high-quality care, measuring the quality of that care to make sure it gets better month by month and year by year, not on saving costs. And I think if we have been able, especially in a closed health care system like the VA, to focus on quality, to take the focus off of cost and rationing and death panels and all that craziness, we really should be able to do it outside the VA.

Diane E. Meier, M.D.: One of the things that actually disturbed me about the 60 Minutes show and some of the other discussion about death panels is that there was no attention to the fact that palliative care is actually about matching treatment to informed patient and family goals. I wonder if the VA has included any measures in its approach to assuring quality that actually look at the concordance of the treatment received to informed patient and family preferences?

David J. Casarett, M.D.: We do. Actually, one of the questions that we ask, which we are now rolling out to every single family member of every veteran who dies in an inpatient facility nationwide, either in acute care or a long-term care setting, is whether there was any treatment that the veteran wanted or needed that he or she did not receive. So that is one way in which we are beginning to explore, at least from the family's perspective, whether there is any treatment that is being or perceived to be withheld inappropriately.

Diane E. Meier, M.D.: And have you gotten pilot data looking at that issue of matching treatment to goals?

David J. Casarett, M.D.: Yes. The numbers are very, very small.

Charles F. von Gunten, M.D., Ph.D.: And yet the VA is an example in which Senate hearings were held and there was a sense of a clampdown on a booklet that was developed for family information about end-of-life care. It seemed like a kind of mob psychology trying to influence care.

David J. Casarett, M.D.: I hesitate to comment on that situation specifically, but I think in general what we saw there with respect to the Your Life, Your Choices book-and more generally what we saw with the death panel discussion, is a complete reframing of the issues. In general we would all agree that the way we view palliative care involvement in general and end-of-life discussions in particular, is a way to make sure that patients and families can express their views, and it is a way for them to make sure that the care they receive is consistent with their goals and preferences.

All of what we are doing is about choice. That is something that I think is very, very hard to argue with. And so in what I think seems to me to be kind of a comic reversal-it would be comic if it were not so tragic-some people have reframed the advance care planning legislation, and to some degree the VA booklet, not in terms of choice, which is really what it is, but in terms of taking away choice. This technique of reversing the argument is a technique to frighten people.

Walter J. Smith, S.J., Ph.D.: I would like to go back to the issue of incentivizing primary care and prevention. This topic is included in both the House and Senate bills and it certainly will be included in whatever reconciled bill that emerges within Congress. This is another excellent opportunity for palliative care to present its philosophy of patient and family care, utilizing this new language. A new platform for payment reform for physicians will be negotiated, focusing on quality and outcome. The Secretary of Health and Human Services (HHS) will play a very significant role in whatever emerges from this legislative effort. As I read the various versions of the proposed bill, the Institute of Medicine will play some role in helping to develop the research and make strategic recommendations to HHS. Palliative care needs to be proactive to ensure that its approaches to care are included in the research protocols and viewed as a way to address the issues of incentivizing primary care and how physicians will be reimbursed for that care.

Diane E. Meier, M.D.: One of my biggest concerns is that all of these inching-toward-capitation models, like accountable care organizations and patient-centered medical homes and bundled payments right now do not contain any requirement for access to palliative care. My concern is that the $5 \%$ to $10 \%$ of patients with five or more chronic conditionsthat is, the sickest patients-are the ones driving over two thirds of the total cost.

In Medicare it is $10 \%$ of patients driving nearly $75 \%$ of total Medicare spending. In the commercial population it is $5 \%$ driving two thirds of the cost. The complexity of this patient population and the fact that most of them are not at the end of life-they have multiple, serious chronic illnesses and are going to live often for years with them-is something not every provider can effectively manage. People with additional training in palliative care or geriatric medicine are going to be critical in order to deliver high-quality care to that patient population. That message heretofore has not been clearly advanced by our palliative care field, in part because, apart from the National Hospice and Palliative Care Organization (NHPCO), the nonhospice elements of the palliative care field have not had sufficient presence on the hill during the reform process.

Clearly, all of those efforts, accountable care organizations, patient-centered medical homes and bundled payments are efforts to get a handle on what many policy makers describe 
as health care policy's "original sin," fee-for-service medicine, where you are not paying for quality or outcomes. You are just paying for volume. And so all the incentives in the system are toward more use, overuse, subspecialization, fragmentation because that is what gets paid for.

As Joan Teno often repeats, the system is perfectly designed to get the results that it gets. And all of these demonstration and pilot efforts are an effort to change those financial incentives toward value, toward quality, and away from volume. But as I said, palliative care needs a seat at that table, and up until now perhaps we have not had enough access to those dialogues.

Walter J. Smith, S.J., Ph.D.: I think that the National Quality Forum (NQF) status of palliative care, in which evidence-based quality measures are linked to reimbursement in all parts of the system, is a real benefit for having a clear voice at the table on this question, Diane.

Diane E. Meier, M.D.: I agree. It is important for people to be aware that the NQF is the major public/private partnership driving measurement and linking reimbursement to quality through measurement. And they have a new initiative about a year old called the National Priorities Partnership, which is a partnership of roughly 30-plus major health care entities in the United States, for example, the American Medical Association, the American Hospital Association, National Institutes of Health, the American Association of Medical Colleges, National Business Group on Health-a broad group of stakeholders in the health care system.

Over an iterative process of a year they identified six priorities for the Partnership that they felt, if advanced, would have the potential to rapidly and substantially improve health care quality. And interestingly among those six priorities, one is palliative care. And palliative care as we define it-that is palliative care that is not linked to prognosis and palliative care that is about matching treatments to informed patient and family preferences and goals.

One of my hopes this year is that being in Washington will help highlight the ways in which the palliative care priority and the National Priorities Partnership can actually exemplify what the NQF is trying to accomplish.

Walter J. Smith, S.J., Ph.D.: I think palliative care has a golden opportunity to do that.

David J. Casarett, M.D.: Diane, do you have a sense of whether there are leverage points in Washington? Not sort of global policy leverage points, but just from the conversations that you have been having and some of the responses that you have gotten during the interviewing process?

Diane E. Meier, M.D.: I think there are a number of planets aligning at the moment. For example, the National Business Group on Health and other entities who are primarily based in Washington are talking about the issue of preferred provider status for commercial insurers, and the notion that in order to receive preferred provider status if you are a hospital, for example, that you would need to demonstrate that you had a palliative care program that met quality guidelines. That is enormously promising, obviously, because the payer has a lot of influence on where health care entities decide to put their resources.
If the payer says, "No palliative care program that meets quality guidelines, no preferred provider status," overnight we would see very rapid change in access to palliative care that met quality guidelines.

The major barrier to accomplishing this objective is that at present we do not have an external body assessing the quality of palliative care programs. The Joint Commission is still considering the release of a palliative care certificate program that actually would recognize palliative care programs for adherence to both clinical and structure and process quality measures. So in order to move toward achievement of requiring a certified palliative care program for eligibility as a preferred provider, we need to encourage the Joint Commission and other accreditation bodies to develop external programs of palliative care certification. These are the kinds of links and connections that it is going to be easier to make hanging out in Washington than hanging out in New York.

C. Porter Storey Jr., M.D.: Is there any way we can make palliative care less "radioactive"?

Diane E. Meier, M.D.: As is often said by people in the media, any media is good media. Remember the Terri Schiavo situation? Many of us were wringing our hands about the kind of attention and publicity that was given to palliative care goals at that time. But in the end, the pendulum swung back, in my view, towards the increased national dialogue about this issue. What is high-quality care for the seriously ill? It actually rebounded to increasing public awareness of what it can be like to be seriously ill in the health care system and what patients and families need to do to assure that they do have choice and they do have control over what happens to them when they fall into the system.

And I actually think the same is true with the death panels. I think most people-they may not be the ones that are on Fox News and they may not be the ones who get the headlinesbut that most people recognize that the death panel rhetoric was hyperbolic, overblown, and being used for political purposes. So in the end, while I was quite worried when it was happening, I think we may have actually enhanced public awareness of the importance of palliative care as a result of all the attention that was given to this issue in August.

Walter J. Smith, S.J., Ph.D.: I agree. There may be a silver lining in all of this. And Porter, I would suggest that members of the palliative care community take every opportunity that is offered by the media to discuss these issues in public forums, no matter how big or small the market opportunity may be. The more people from the diversity of disciplines that comprise palliative care teams who speak to these issues, the more informed the conversation will be.

Too many knowledgeable people have remained silent and have not seized the media opportunities to address these questions. Because these topics are so current, many media outlets are looking for people like us to interview or debate. I have participated in two of these types of programs within the past week.

The opportunity here is unparalleled. Diane is right that a public conversation has been avoided, but the bubble of defensiveness of talking about people who have serious lifelimiting illnesses or debilitating illness and facing death has been burst. This "death panel" issue has opened up the 
conversation in ways that would have been very hard to engage otherwise.

Charles F. von Gunten, M.D., Ph.D.: The way Diane phrased her position is a way that I have found useful and I think perhaps this is the kind of language we need to give those in our field who do not have a chance to practice. It is daunting to engage in a conversation on the radio or television with someone who brings up the death panel language or says palliative care is just a euphemism for rationing. To be prepared to say boldly that most Americans are not going to be swayed by this kind of fear mongering. Direct confrontation and stating a positive position is not usual in patient care interactions, where we try to steer conversations rather than an upfront, bold statement saying, "Most Americans are not going to believe this because it is just not true." Do you agree?

David J. Casarett, M.D.: I agree, but we have been talking about how to react as a community to some of the things that hit the media. Being reactive is probably not as good as being proactive. Also, I think when we are being reactive, it can be a little bit harder to come up with a unified message because it is a lot of us trying to react very quickly.

You get a call from Melissa Block's assistant at NPR asking if you could be on their show in 2 hours. Many of us get these requests and so it is tough to come up with a unified message in those circumstances. Although I do agree that this is a huge opportunity, which I think as a community we are able to take advantage of. I also think we will be missing the boat if we are not more proactive crafting a message and getting that message out whether there is anything brewing or not. I was at a meeting last week in Washington that the Clinton Foundation sponsored to talk about pain and palliative care in underdeveloped countries. Meg O'Brien, who was the point person from the Clinton Foundation said, "This issue of pain and palliative care really needs a rock star." She meant it really needs somebody who is very, very visible. Not necessarily somebody from the palliative care community, but I think she meant literally sort of a rock star to do for palliative care what, say, Bono has done for global poverty.

And I guess I am not making this as a suggestion necessarily, but I would be interested in the group's thoughts about whether we need sort of the equivalent of a rock star or a group of rock stars who, just because of who they are, have instant visibility and who can at least be one of the faces, if not the most public face of the message that we are trying to deliver sort of across the board, day after day, month after month, whether or not there is a breaking news story or not.

Diane E. Meier, M.D.: At the Center to Advance Palliative Care, we have been trying for about 3 years now to raise between $\$ 6$ and $\$ 10$ million to do a large national social marketing campaign, of which rock stars (pleural) would have to be a part. But the key to a social marketing campaign is repetition and use of multiple communication platforms such as social web 2.0, TV, radio, print media. The problem is that doing it right is very expensive, and it is tough to get private sector philanthropy to invest in social marketing, as opposed to direct service to patients.

It remains a high fundraising priority for me personally and for the Center to Advance Palliative Care generally because I think if we do not start driving the demand side and make the public more sophisticated about what quality of care looks like and what to ask for, we are talking to ourselves. We are not going to see the supportive policy change and improvement in the care that our fellow citizens receive without it. I strongly agree with what you are saying David.

Charles F. von Gunten, M.D., Ph.D.: Porter, do you have a point of view from the Academy in terms of marketing efforts and trying to change public opinion?

C. Porter Storey Jr., M.D.: We (AAHPM) recently received a grant to put the website palliativedoctors.org up to present some good patient stories and information about what palliative care really is, in a language that people can understand. We are continuing to try to give our members the tools they need to carry this message.

We are also relooking at our representation in Washington to try to make sure we have the most effective representation not only on the Hill, but in public relations efforts. I do think that the professional associations have a role here in helping get the message out to members and to really encourage them to take the opportunities to dispel some of these fears and bring attention to the good care we really are providing.

David J. Casarett, M.D.: One thought occurs to me. Although we have been focusing on palliative care, obviously we are in the back of our minds, at least I am, including hospice in that. It strikes me that hospice organizations are an enormous network, not just almost 5000 hospices around the country, but all of those hospices have staff. And more importantly, those hospices have large populations of volunteers, many of whom are financial supporters of hospice as well.

So in thinking about strategy and thinking about social marketing and thinking about getting a message out, we should also think creatively about how to use that population of people and their families who are being served by hospice or who have and have remained connected to the hospice community because presumably they value what hospice does.

Beginning to harness that energy and that goodwill will only help us across the board. And I think whatever helps the hospice industry will also help us who do palliative care outside of hospice.

Diane E. Meier, M.D.: I agree. The overarching theme of this-even the headline, perhaps, of this dialogue that we are having, should be that palliative care is about matching treatment to patient goals. That is the message that everybody in the field of hospice and palliative care should be carrying forward.

Walter J. Smith, S.J., Ph.D.: I agree with Diane that it is exceedingly difficult to attract the philanthropic support for the kind of social marketing program that would be needed to saturate the media in a sufficient way to change people's perceptions and therefore their behaviors. But I do think that there are secondary ways of doing that.

Assuming that Congress will be successful in passing this comprehensive health care reform legislation-the focus is going to be on the implementation of what these new programs must do to effectively improve quality and slow the growth of the total health care spending in the nation.

And I think this is a platform that palliative care proactively needs to seize by saying "And that defines exactly who we are and what our goals are." 
Families are looking to get better care for their loved ones. As Diane defines it, this is what palliative care does so well. If that is the message, then it should be repeated as the answer to every reporter's question. In lieu of having its own resources to mount a comprehensive social marketing campaign, palliative care needs to be positioning itself to jump on every other marketing opportunity and to be offering its approaches to patient-centered care as a solution to the questions of quality and effectiveness.

C. Porter Storey Jr., M.D.: Walter, do you think there is any possibility of getting funding for home-based palliative care? This is one of the big holes that I see.

Walter J. Smith, S.J., Ph.D.: I do not see why not. Once people understand the "what," I think "how" it is done and funded will follow. Hospice care is already well established as a home care model; providing palliative care at home makes sense both economically and in terms of optimizing care. I think that it would be an easy sell to most consumers, payers and philanthropists. Foundations that are looking to support inventive health care delivery programs, which will really make a difference and be cost-contained, would certainly be receptive.

C. Porter Storey Jr., M.D.: The Kaiser experience has been that hospital-based programs can be markedly effective, but they are much more effective if there is a home-based palliative care program to receive these people after the hospitalization and continue the symptom management and family support.

I am now doing clinic-based palliative care work, and we are getting a marvelous opportunity to see people farther upstream. If there was funding for these services, I think they could be available to a lot more people.

Walter J. Smith, S.J., Ph.D.: Anything that addresses productivity improvement is going to garner interest through the research programs that the government will be looking to fund. That is why I spoke earlier about the opportunities at the Institute of Medicine (IOM).

Historically, the IOM has been somewhat resistant to initiatives in integrative medicine and palliative medicine. This is a nonphysician and nonmember's impression. But last year there was a very successful symposium on integrative medicine hosted by the IOM. In fact, it was the largest public program that the Institute ever mounted. I think it surprised the leadership of the Institute of Medicine that this symposium garnered as much popular interest as it did. It would be opportunistic to build on this momentum and for palliative medicine to further strengthen its alliances within the Institute of Medicine. I think IOM has reasonable leverage in Washington and could channel some of the research money to palliative care initiatives that aim to stimulate productivity improvement.

Diane E. Meier, M.D.: Since it has been more than 10 years since Approaching Death was released, it is time for the Institute of Medicine to do another report on palliative care, more broadly construed this time than end-of-life care.

Walter J. Smith, S.J., Ph.D.: Well, during that Integrative Medicine conference, I spoke with the president of the IOM. I would say that palliative care is the primary operational definition of integrative medicine.
Charles F. von Gunten, M.D., Ph.D.: I wonder if we might go around for last words-particularly targeting advice to those people who are not in leadership roles. What should they be doing when this kind of discussion falls in their lap?

Walter J. Smith, S.J., Ph.D.: Palliative care providers have been working quietly in the trenches, caring for very diverse patients with serious and complex health problems, and with their loved ones. As such, they have more experience in organizing and providing quality care than virtually any other primary care provider. Palliative care needs to be more visible and proactive in speaking to that experience and documenting what a difference integrative care makes when families with all of these complex needs are cared for in a coordinated way.

Palliative care also subscribes to the premise that measuring quality and effectiveness are normative for its practice. I believe that palliative care is developing an evidence base from which it can speak with authority and conviction.

In sum, palliative care has a singular opportunity to selfdefine its approaches to care and to advocate for this as a model for the way all care in a new health care economy should be organized and delivered.

C. Porter Storey Jr., M.D.: To do effective palliative care, we have to learn to listen, to become advocates for our patients and to work in other cultures, like hospitals, in order to help our patients navigate the system and get the care they are looking for. I think these skills are applicable more broadly. If we use these skills to help our community at large see that palliative care really offers a lot of what the health care system needs now, that we will be much more successful politically as well as clinically.

David J. Casarett, M.D.: I think that, as palliative care providers, we advocate for a patient's and family's needs and interests. I think this is one opportunity in which we can advocate on a more global stage, not necessarily at the bedside, but in Washington.

However, to do that, just as we often in clinical work have to overcome some of our fears and reluctance, we have to do that here, too. I think one big fear that many of us have is a fear of being measured, a fear of being held accountable for what we do. For a long time, hospice and palliative care has been exempt from quality measurement and accountability. I think that is going to change, and I think it probably should change.

Really, the most effective way to advocate for the needs of our patients and families is if we know how well we are doing, if we know something about the care that our patients and families are receiving, and arguably if our patients and families know about the quality of care that they are receiving or that they are likely to get from a particular facility or health care system.

So I think to be effective advocates, we are increasingly going to have to be willing to embrace quality measurement and accountability. And we should be leading that charge.

Charles F. von Gunten, M.D., Ph.D.: Diane, we will give you the last word.

Diane E. Meier, M.D.: I feel, first of all, grateful for this opportunity. My message is that we have to be careful about how we explain ourselves, not only to our patients and 
families and to our colleagues, but to the public at large and that we need to keep our focus on palliative care as a means of matching medical care to patient and family goals.

It is not about anybody's agenda other than that of the patient and family, and I think we must keep saying that. We should stop saying we want people to have a good death or that we want to be more efficient or we want to stop those other doctors from doing the wrong thing. If we keep our focus on the patient and the family in front of us and help them come to an understanding of their situation and help them identify the priorities that are meaningful for them, we are true to the principles of palliative care. I think that it is something that the public not only can understand but will embrace.

Address correspondence to: Diane E. Meier, M.D. Center to Advance Palliative Care Hertzberg Palliative Care Institute Departments of Geriatrics and Internal Medicine Mount Sinai School of Medicine

Box 1070

New York, NY 10029

E-mail: diane.meier@mssm.edu 